\title{
RECORDING AND MODELING OF FORTRESSES AND CASTLES WITH UAS. SOME STUDY CASES IN JAEN (SOUTHERN SPAIN)
}

\author{
J. Cardenal ${ }^{\mathrm{a}}$ *, J.L. Pérez ${ }^{\mathrm{a}}$, E. Mata ${ }^{\mathrm{a}}$, J. Delgado ${ }^{\mathrm{a}}$, J.M. Gómez-López ${ }^{\mathrm{a}}$, C. Colomo ${ }^{\mathrm{a}}$, A. Mozas ${ }^{\mathrm{a}}$ \\ ${ }^{a}$ Department of Cartographic, Geodetic and Photogrammetric Engineering. University of Jaen. 23071-Jaen (Spain) - (jcardena, \\ jlperez, emata, jdelgado, antmozas)@ujaen.es, (jmgl0003, cmcj0002)@red.ujaen.es
}

Commission V, WG V/2

KEY WORDS: UAS, heritage documentation, Iberian and medieval Spanish fortresses, SfM software

\begin{abstract}
:
The province of Jaen (Southern Spain) has one of the largest concentrations of medieval fortresses of all Europe. Moreover ancient Iberian settlements located in oppida (fortified villages) and dated at VI-IV BC also are outstanding examples of historical heritage landmarks in the region. Most of these places are being restored or under documentation analysis to prevent their progressive deterioration. These places have several geometric characteristics in common, such as isolated locations, elongated shapes, largemedium size objects (in the order of tens to few hundred of meters), architectural features with vertical development (such as masonry or rammed earth walls, towers, gates, battlements, etc) or without it (walls, buildings or paths layouts at ground level). The object size, the required level of details and accuracy (of the order of some few $\mathrm{cm}$ ) and both vertical and horizontal features imply that present UAS techniques can be advantageously used with respect to conventional aerial and terrestrial photogrammetric techniques. Vertical stereoscopic and oblique convergent UAS photogrammetric networks combined with processing techniques based on Structure from Motion (SfM) algorithms allow detailed low cost 2D/3D products. The proper selection of the UAS, camera, image acquisition mode (stop and/or cruising), the network and the processing software will determine the quality of final products and their usefulness in metric documentation, 3D modelization or museology. The efficiency of the use of UAS has been analyzed in several selected examples in Jaen (Burgalimar and Berrueco castles, Xth and XIIIth centuries, respectively, and the Iberian Puente Tablas oppidum, Vth-IVth centuries BC).
\end{abstract}

\section{INTRODUCTION}

\subsection{UAS techniques for heritage documentation}

In any heritage documentation study, a geomatic survey of the site is essential. The terms of this survey will depend on the final products (topographic maps, digital elevation models DEM's-, orthoimages, VRML models, etc.) and the technical specifications needed to obtain them (working and output product scales, accuracies, available instruments, data acquisition and reduction methods, costs, etc.). Photogrammetric techniques, both aerial and terrestrial, have largely been employed in this type of survey.

Aerial techniques can be an optimal solution in the case of medium-sized and large heritage sites, since the possibility of raising sensors and capturing the information, in many cases rather difficult to obtain at ground level, can increase the performance of photogrammetry.

Moreover, unmanned aerial systems (UAS) are nowadays increasingly used in applications for heritage documentation (Sauerbier and Eisenbeiss, 2010; Eisenbeiss and Sauerbier, 2011; ISPRS, 2013). One of the main reasons is based on the conditions of these sites and the usual resolution requirements which oblige to use close range acquisition techniques (low flying heights). These conditions, as well as cost constraints, limit the use of conventional planes used for lower scales' mapping.

But the present extensive use of UAS has also been given by the dropping prices, the miniaturization and new high performances of these systems and recent developments with respect to GNSS and inertial systems, autopilot guiding advances, etc. But also the current state of applicability is due to the use of new algorithms from computer vision. Indeed, a new generation of low cost and user-friendly photogrammetric software based on dense matching and Structure from Motion (SfM) approaches has also contributed to this dramatic increase of UAS applications on cultural heritage.

Present UAS, combined with SfM, keep moderate costs and they are suitable for small areas. Additionally, they can be used for the acquisition of very high-resolution images where both texture and geometry information enable not only architectural and archaeological analysis (from analog maps and plans, orthoimages, Digital Surface Models, 3D models, etc.) but also allow visually attractive visualisations and virtual products.

\subsection{Aims of the work}

This paper aims to analyse the use of UAS for the documentation and modelling of fortresses, walled sites and castles. These places have several geometric characteristics in common, such as isolated locations, elongated shapes and a large-medium size, in the order of tens to few hundred of meters.

They present architectural features with vertical development (such as masonry or rammed earth walls, towers, gates, battlements, etc.) or without it (walls, buildings or paths layouts at ground level).

The object size, the required level of details and accuracy (of the order of some few $\mathrm{cm}$ ) and both vertical and horizontal features (adequately surveyed from oblique and vertical photographs, respectively) imply that present UAS techniques can be advantageously used. 


\section{CASE STUDIES}

\subsection{Fortresses and castles in Jaen (Southern Spain)}

The province of Jaen (Southern Spain) has one of the largest concentrations of medieval fortresses of all Europe (EslavaGalan, 1999). During centuries Jaen was the frontier between the Muslim and Christian kingdoms.

Most of these places are being restored or under documentation analysis to prevent their progressive deterioration. Moreover ancient Iberian settlements located in oppida (fortified villages) and dated at VII-III BC also are outstanding examples of historical heritage landmarks in the region (Ruiz and Molinos, 2015).

Three case studies have been selected in the province of Jaen. The first one is the Iberian Puente Tablas oppidum, Vth-IVth centuries BC (Figure 1), while the others are two castles, the Burgalimar Castle (Xth century; Figure 2) and the Berrueco Castle (XIIIrd century; Figure 3).

These sites present architectural features with vertical development (walls and towers) of different height between 2$25 \mathrm{~m}$. But on the other, these sites consist of the remains of buildings, rooms and paths with the walls still visible, although the height of the preserved structures is less than $1 \mathrm{~m}$.

These geometric features imply that vertical and oblique image blocks configurations are needed for a proper survey of these sites.

\subsubsection{Iberian Puente Tablas oppidum (Vth-IVth centuries} BC; Lat, Lon: $\mathbf{3 7 . 8 1 3 0}^{\circ},-\mathbf{3 . 7 4 8 3}^{\circ}$ ): The Puente Tablas oppidum is located on the top of a flat hill at $5 \mathrm{~km}$ from the city of Jaen. The size of the site is approximately $400 \mathrm{~m}$ length and $280 \mathrm{~m}$ width and it has been being excavated from the end of the nineteen seventies until present.

It presents a defensive wall (near $400 \mathrm{~m}$ length) in the eastern part with eight bastions. Although scarcely $15 \%$ of the site has been excavated, geophysical prospection has shown that a complete urban network appears to exist.

Also it can be highlighted the presence of a palace and an entrance gate to the oppidum where evidences of solar rituals and a sanctuary have been revealed.
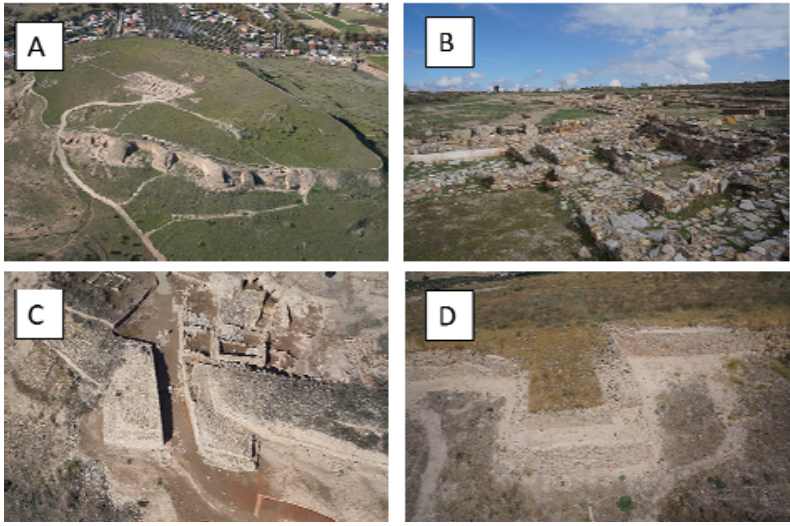

Figure 1. Iberian Puente Tablas Oppidum (Vth-IVth BC). A: Aerial view; B: village; C: Entrance gate and sanctuary; D: details of a section of the walls and a bastion.
2.1.2 Burgalimar Castle (Xth century; Baños de la Encina, Jaen; Lat, Lon: $\mathbf{3 8 . 1 7 0 2}^{\circ}$, $-\mathbf{3 . 7 7 5 4}^{\circ}$ ): The Burgalimar Castle (Figure 2) is a fortress dated at Xth century during the Ummayad rule of Al-Andalus (Moorish Iberia).

It is built on the top of a rocky hill and dominates the surrounding area. It is oval in shape (100 m length and $46 \mathrm{~m}$ width).

The defensive wall (earth rammed built) consists in 14 quadrangular towers where the original curtain walls, battlements, wall-walk, and arrow slits still remain as well as the two horseshoe arches of the entrance.

A masonry keep tower was added in XVth century with another circular lower tower which encloses the inner ward.

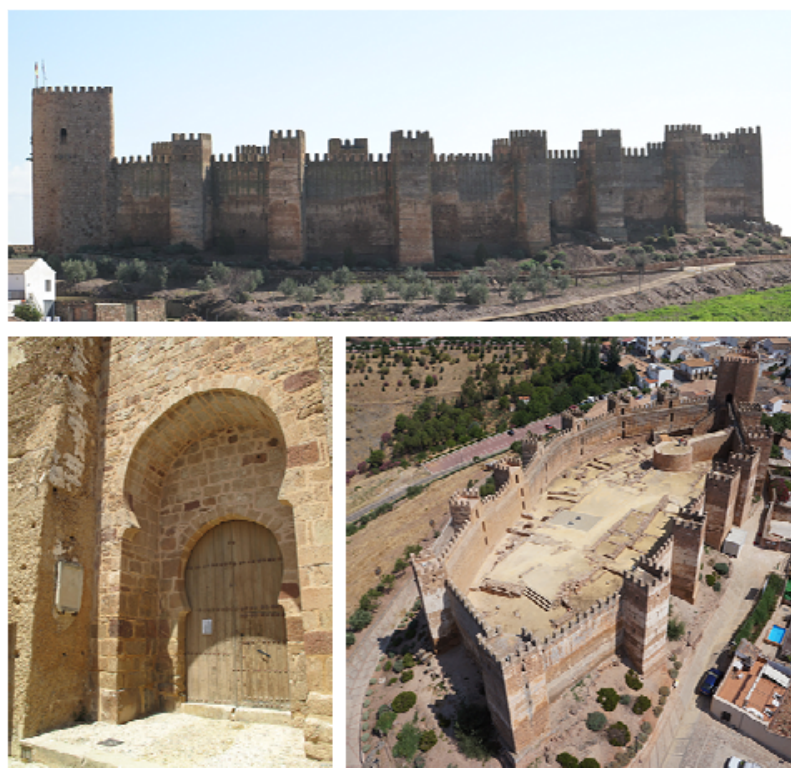

Figure 2. Burgalimar Castle (Xth century). Top: General view, the keep tower was built in XVth century; Lower left: horseshoe arch at the main entrance. Lower right: aerial view from the UAS.

2.1.3 El Berrueco Castle (XIIIrd century; Torredelcampo, Jaen; Lat, Lon: $37.8654^{\circ},-3.9386^{\circ}$ ): The third example is the Berrueco Castle, XIIIrd century, a small rural castle built after the Jaen area was conquered by the Kingdom of Castile (Figure 3).

The castle is located on a rocky spur and it is rectangular in shape (65 m length and $26 \mathrm{~m}$ width) with two circular towers. Although the state of conservation is deficient, a section of a curtain wall with the original wall-walk and battlements are still relatively well preserved.

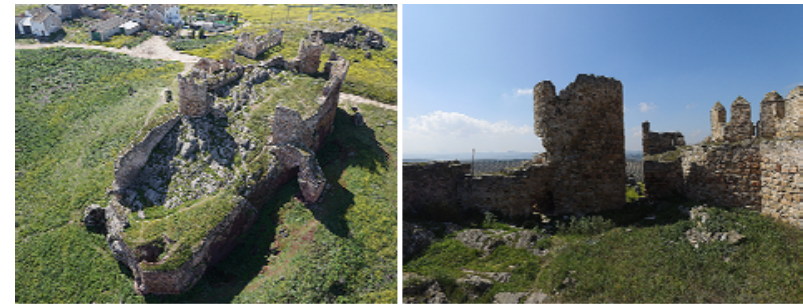

Figure 3. Berrueco Castle (XIIIrd century). Left: aerial view; Right: original battlements and wall-walk. 


\section{INSTRUMENTATION AND METHODS}

\subsection{Instrumentation}

The UAS employed in this work has been an 8- rotors AscTec Falcon 8 (Figure 4) coupled with GNSS/INS and equipped with a MILC (mirrorless interchangeable lens camera) Sony NEX 5N (APS-C format, $16 \mathrm{Mpx}$, pixel size $4.9 \mu \mathrm{m}$ ). The lens is a Sony E $16 \mathrm{~mm} \mathrm{f} / 2.8$ fixed focal length $(24 \mathrm{~mm}$ in equivalent $35 \mathrm{~mm}$ format). The MTOW is $2.3 \mathrm{~kg}$ and the speed is in the range of 4.5 to $15 \mathrm{~m} / \mathrm{s}$ depending on the flight mode (manual, height or GPS mode).

This UAS was upgraded to the new Asctec Trinity system with improved performances with respect to redundant inertial measurement unit, flight control and dynamic (ASCTEC, 2016). Both mission planning and flight were assisted by the AscTec Navigator system.
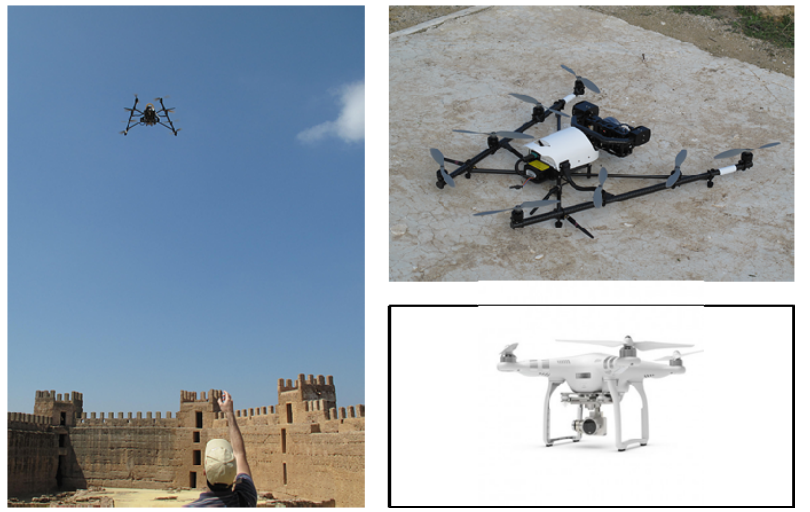

Figure 4. UAS used in this work. Left and upper right: AscTec Falcon 8. Lower right: Phantom DJ 3 Advanced.
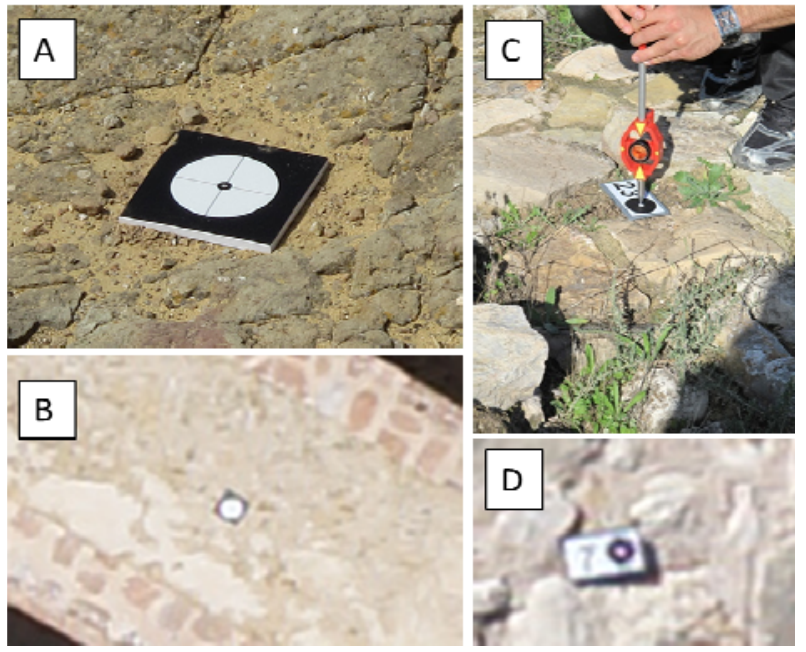

Figure 5. Circular targets used as GCP. A: Target for GPS measurements; B: Aerial view of target A at 50 flying height. C: Target for total station and mini prism pole measurement; $\mathrm{D}$ : Target $\mathrm{C}$ at $20 \mathrm{~m}$ flying height.

Additionally, another UAS, a 4-rotor DJI Phantom 3 Advanced (Figure 4), was used. This UAS, GPS/GLONASS-assisted, is equipped with a Sony EXMOR camera and a $3.6 \mathrm{~mm} \mathrm{f} / 2.8$ lens (20 mm in equivalent $35 \mathrm{~mm}$ format). This small compact camera (1/2.3” format, $12 \mathrm{Mpx}$, pixel size $1.6 \mu \mathrm{m})$ is installed in a 3-axis brushless gimbal. Blocks were oriented in ETRS89/UTM 30N coordinate reference system using field surveyed ground control points (GCP). The GCP were white/black circular targets of different diameters depending on the flying height. These targets were measured by means of DGPS (LeicaSystem 1200 and Leica Viva), although in some limited areas, GCP were measured with a total station (TCRA 1203 Leica) and a mini prism (Figure 5).

Images were mainly processed with PhotoScan (Agisoft) and to a lesser extent Pix4D. Additional edition tools from Socet Set DPW and I-Site Studio (MAPTEK) were used.

\subsection{Network geometries}

Planning UAS projects is a challenge task since they are a combination of conventional aerial photogrammetric projects with those of convergent close range networks under special constraints (spatial, large height and depth differences, obstacles, wind, battery use, legal aspects, etc.). Although available mission planning software facilitates this step, most of these systems are valid to plan flight projects using orthos or rectified images without any information of height differences. While this planning will suffice most projects for $2 \mathrm{D} / 2.5 \mathrm{D}$ products with vertical images in plain areas, problems can arise in case of the usual large height differences in fortresses, so overlaps and GSD can be largely affected.
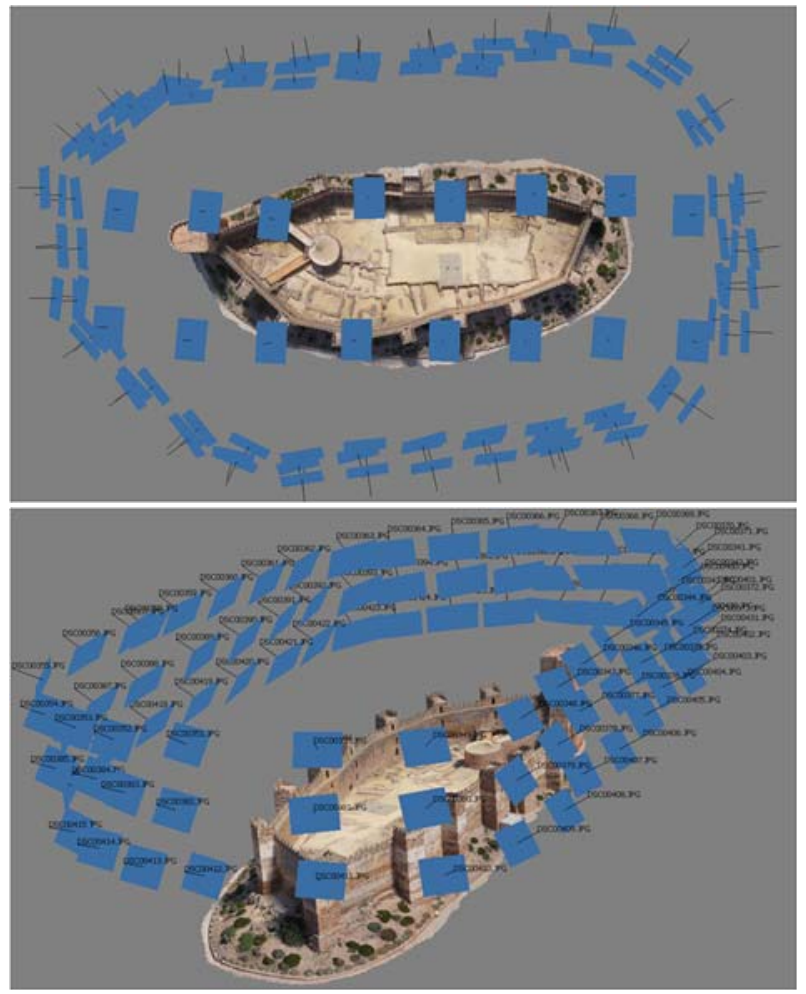

Figure 6. Network geometry at Burgalimar Castle (107 images). Upper: conventional vertical network (2 strips, 16 images). Lower: convergent and oblique network around the castle. Three strips at different height were planned (91 images). The image acquisition mode was stop-mode.

But in the case of oblique images for surveying near vertical features, additional calculations have to be made to select a 
proper GSD, the camera tilts and aims, sidelaps, flight lines at different heights to avoid hidden areas, etc. (Figure 6).

The selection of the take-off point is also crucial since the height of the flight lines will be measured from the height of the starting point.

In any case, large overlaps (around 80\%) in both vertical and oblique flight lines are recommended to avoid hidden areas and loss of coverage. But also large endlaps and sidelaps allow strengthening the photogrammetric networks and reducing the number of GCP along and across the strip lines, since general rules for ground control in aerial triangulation are applicable (Kraus, 2007).

\subsection{Image motion: UAS speed and exposure times}

Heritage applications need relatively close range object-camera distances because GSD requirements are usually in the $\mathrm{cm}$ range. Since UAS are mobile platforms, there are several critical factors to be taken into account in order to avoid blurred images due to image motion. Image motion will depend on UAS speed, exposure time, object-camera distance as well as some side rotational motions (both aircraft and camera mount) and wind gusts.

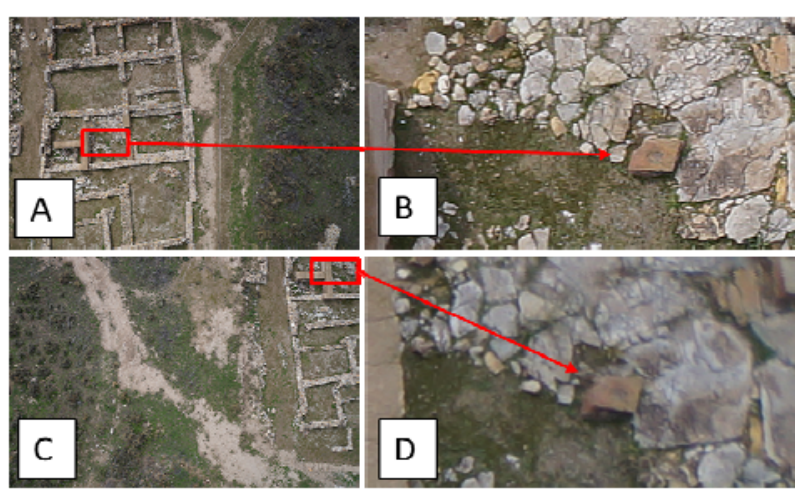

Figure 7. Sony NEX 5N images (A, C) acquired in stop-mode with the UAS hovering above the terrain at $20 \mathrm{~m}$ height (village sector at Puente Tablas Oppidum). The effect of blurring in the image corner in image $\mathrm{C}$ is evident (D) with respect to the mid-section of the frame in image A (B). Exposure values for both images were $1 / 640 \mathrm{~s}$ and $\mathrm{f}$ 5.6. This blurring effect at the image edges increases with wider lens apertures. So the faster is the exposure time, the wider must be the aperture, so blurring at the edges increases.

Image acquisition modes (manual, stop or cruising; Eisenbeiss and Sauerbier, 2011) are of interest in this matter since the speed is one of the key issues. With image acquisition stop mode the UAS hovers around a predefined waypoint, so motion is reduced to the stabilization of the platform on the planned waypoint. The authors' own experience with the Falcon 8 and the Sony Nex $5 \mathrm{~N}$ camera and $16 \mathrm{~mm}$ lens shows that an exposure time (ET) between 1/640-1/800 s is enough for sharp images under gust wind conditions in the range of 2-3 Bft scale $(2-5 \mathrm{~m} / \mathrm{s})$. Faster ET would be more favourable but they can result in underexposed images (depending on light conditions, shadows, etc.). Additionally an image quality worsening can occur. If a faster ET is set on the camera, a wider lens aperture will be selected by the shooting mode (shutter priority). Image sharpness decreases with wider apertures especially towards the image edges (Figure 7). Indeed the image quality of the lens of
MILC and compact cameras is not so good as the general quality of those larger DSLR lenses.

But since cruising mode is more efficient with respect to the total flying time and battery use, better performance can be attained with this mode. So the UAS speed, the flying height and exposure times need additional attention. While the forward motion compensation (FMC) is routinely used with conventional aerial mapping digital cameras, FMC is not possible with off-the-shelf cameras, although some experiences in post-processing of UAS images for eliminating motion blur distortions have been successfully applied (Chabok, 2013). So in order to avoid blurred images, the image motion should be kept in values lower than 1pixel. The motion error can be calculated from equation 1 :

$$
m_{p i x}=V \cdot t \cdot \frac{f}{H_{f} \cdot p_{x}}
$$

where $\mathrm{m}_{\text {pix }}$ is the motion error (in pixels), $\mathrm{V}$ is the speed of the UAS, $t$ is the exposure time, $f$ the focal length, $H_{f}$ the flying height above the terrain and $p_{x}$ is the camera pixel size. So given a fixed motion error of 0.5 pixels, several combinations between UAS speed and exposure times can be found for a selected flying height (Figure 8).

As shown in Figure 8 (estimated for the Sony camera/lens employed in this paper) for a flying height of $80 \mathrm{~m}$ at a speed of $10 \mathrm{~m} / \mathrm{s}$, an ET of 1/800 s keeps a motion error at 0.5 pixels. But if the height decreases at $50 \mathrm{~m}$, the ET should be set at 1/1250 s. Most multi-rotor systems speeds are in the range of 3-15 m/s, so cautions in selecting speed and ET should be taken specially at low flying heights or close range oblique images.

In any case, as it was mentioned before, faster exposure times might be considered if lighting conditions are acceptable and wider lens apertures do not worsen significantly the image quality (Figure 7).

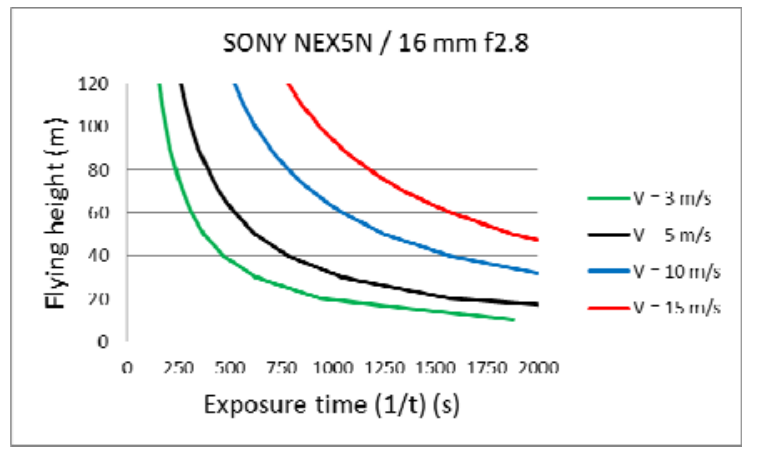

Figure 8. Acceptable exposure times for different flying heights above terrain at given UAS speeds to keep motion error at 0.5 pixels for the Sony NEX 5N-16mm.

\section{APPLICATIONS AND RESULTS}

\subsection{Iberian Puente Tablas Oppidum}

A multi-scale survey was carried out in the Puente Tablas Oppidum. Several independent areas were surveyed with different networks and flying heights (Table 1; Figure 1).

First a global documentation of the site was planned from a conventional UAS aerial survey. Given the area size (400 m x $380 \mathrm{~m}$ ), a resolution of $5 \mathrm{~cm}$ was selected. 


\begin{tabular}{|l|c|c|c|c|c|c|c|c|c|c|}
\hline \multicolumn{1}{|c|}{ Area/UAS } & $\begin{array}{c}\text { No. } \\
\text { images }\end{array}$ & $\begin{array}{c}\text { Height } \\
(\mathbf{m})\end{array}$ & $\begin{array}{c}\text { GSD } \\
(\mathbf{m m})\end{array}$ & $\begin{array}{c}\text { RMSxy } \\
(\mathbf{m})\end{array}$ & $\begin{array}{c}\text { RMSz } \\
(\mathbf{m})\end{array}$ & $\begin{array}{c}\text { Sigma } \\
\mathbf{( \mathbf { p i x } )}\end{array}$ & $\begin{array}{c}\text { Acquisition } \\
\text { mode }\end{array}$ & $\begin{array}{c}\text { V } \\
(\mathbf{m} / \mathbf{s})\end{array}$ & GCP/CHK & $\begin{array}{c}\text { Network } \\
\text { geometry }\end{array}$ \\
\hline Oppidum (PT)/F8 & 66 & 120 & 38.3 & 0.034 & 0.057 & 0.67 & Cruising & 5 & $11 / 8$ & $\mathrm{~V}$ \\
\hline Gate (PT)/F8 & 30 & 35 & 11.2 & 0.017 & 0.003 & 0.60 & Stop & --- & $4 / 3$ & $\mathrm{~V} / \mathrm{O}$ \\
\hline Palace (PT)/F8 & 34 & 33 & 10.5 & 0.022 & 0.006 & 0.52 & Stop & --- & $6 / 4$ & $\mathrm{~V} / \mathrm{O}$ \\
\hline Walls (PT)/F8 & 59 & 28 & 8.9 & 0.014 & 0.014 & 0.57 & Stop & --- & $6 / 6$ & $\mathrm{~V} / \mathrm{O}$ \\
\hline Village (PT)/F8 & 43 & 20 & 6.4 & 0.006 & 0.017 & 0.54 & Stop & --- & $15 / 12$ & $\mathrm{~V}$ \\
\hline Burgalimar Castle/F8 & 107 & 55 & 16.9 & 0.021 & 0.019 & 0.60 & Stop & --- & $24 / 7$ & $\mathrm{~V} / \mathrm{O}$ \\
\hline El Berrueco Castle/F8 & 100 & 46 & 14.1 & 0.015 & 0.012 & 0.90 & Cruising & 6 & $5 / 3$ & $\mathrm{~V} / \mathrm{O}$ \\
\hline El Berrueco Castle/DJ & 115 & 24 & 10.1 & --- & --- & 1.15 & Manual & -- & $4 / 0$ & $\mathrm{~V} / \mathrm{O}$ \\
\hline
\end{tabular}

Table 1. Main flight parameters and quality of georeferencing using PhotoScan in the case studies at Puente Tablas Oppidum (PT), Burgalimar and Berrueco castles. Check points were used to derive RMS values. GCP/CHK refers to the number of GCP and check points used. The network geometry refers to only vertical image blocks or both vertical and oblique image blocks. UAS: F8 (AscTec Falcon 8); DJ (Phantom DJ 3 Advanced).

The flying height above the oppidum was $120 \mathrm{~m}$ since 400 feet, approximately $120 \mathrm{~m}$, is the maximum height limit allowed by the Spanish regulations on the use of remotely piloted aircrafts (BOE, 2014).

Five strips were necessary to cover the whole site. The UAS speed was $5 \mathrm{~m} / \mathrm{s}$ in cruising acquisition mode. A DSM and an orthoimage were generated (Figure 9).

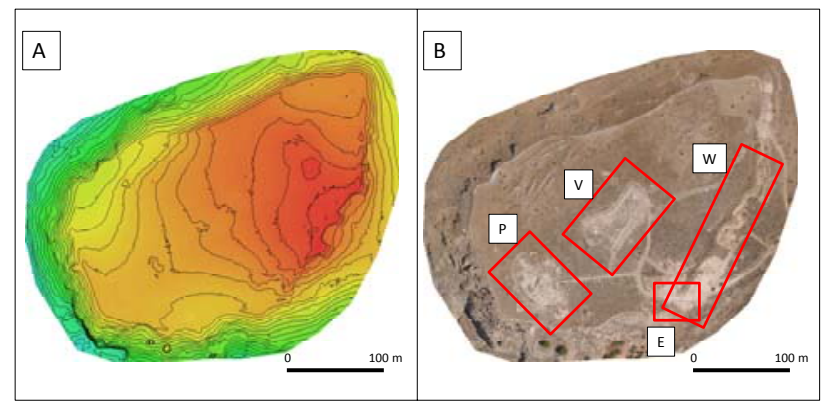

Figure 9. DSM, $10 \mathrm{~cm} \mathrm{(A)} \mathrm{and} \mathrm{orthoimage} 5 \mathrm{~cm}$ (B) of Puente Tablas Oppidum from UAS. Several areas of interest are signalled: Palace (P); Village (V); Gate (E); Walls and bastions (W).

Additional surveys were carried out in different areas of the oppidum. Some of these sectors have been recently excavated and restored. Since the intended resolution was higher $(1-2 \mathrm{~cm})$, flying heights were lower. Most of these new sectors present walls and vertical features in the range of 1-3 $\mathrm{m}$ (Gate and Walls), so oblique image networks were necessary.

In the case of the Village area an orthoimage of $1 \mathrm{~cm}$ was needed (Figure 10), so the GCP were measured with a total station and a mini prism pole (Figure 5) in order to achieve a proper accuracy.

Since the height of the preserved structures (walls, rooms, paths, etc.) was less than $1 \mathrm{~m}$, only a vertical stereo coverage was planned with 5 strips. Images were processed with PhotoScan and Socet Set with addition of break lines to improve the mosaic and the final orthoimage.

Next sector comprises the walls and bastions of the oppidum (Figure 11). Three strips (70\% overlap) were necessary, one vertical and two oblique at different distances to get a homogeneous GSD at the walls and bastions. The DEM was edited with I-Site Studio software (Figure 12).

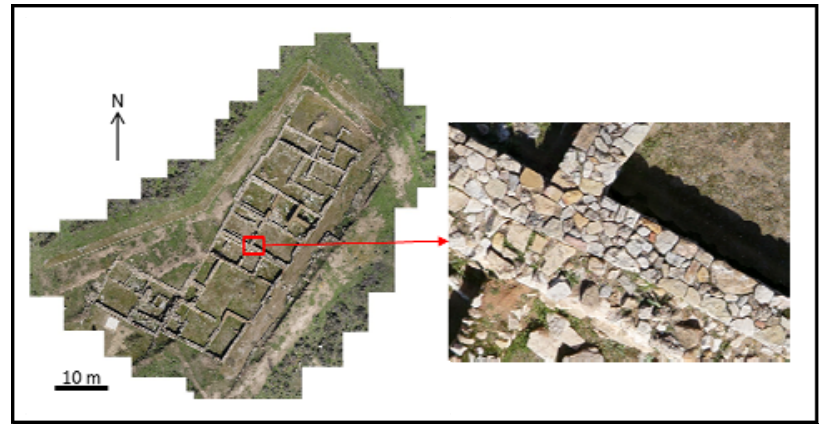

Figure 10. Orthoimage (1 $\mathrm{cm}$ resolution) of the Village (V) sector in Puente Tablas Oppidum.

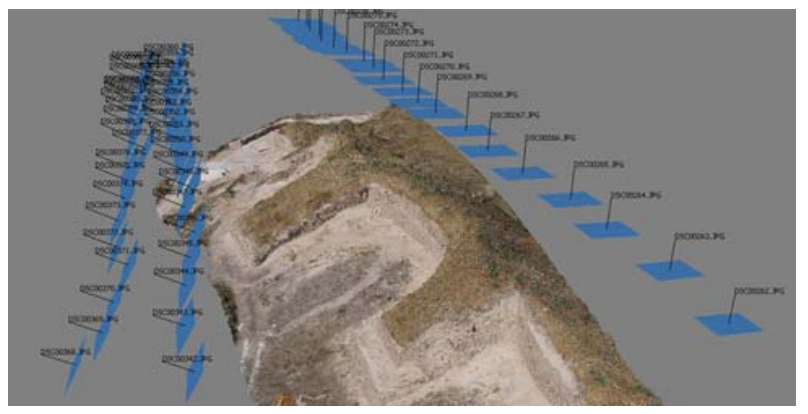

Figure 11. Flight strips above the walls and bastions.

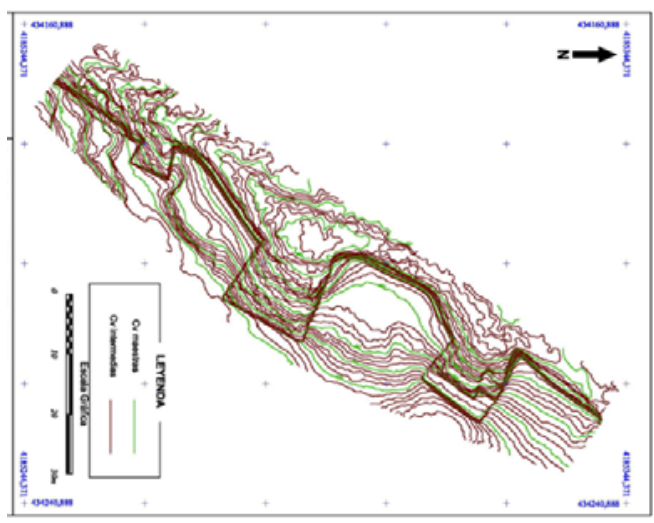

Figure 12. Contour map (derived from DEM), $0.25 \mathrm{~m}$ interval, in a sector of the oppidum wall (Buzdugan, 2013). 
The Palace and the Gate where also surveyed from vertical and convergent oblique images. The Gate is adjacent to a sanctuary and the height of the walls in the area reaches $2.5 \mathrm{~m}$. Evidences of solar rituals during equinox and solstice related to the location of the Gate have been discovered (Figure 13; Ruiz and Molinos, 2015). In these sectors, several products such as orthoimages (1-2 cm resolution), DSM, 3D models and walkthrough videos were generated (Figure 14).

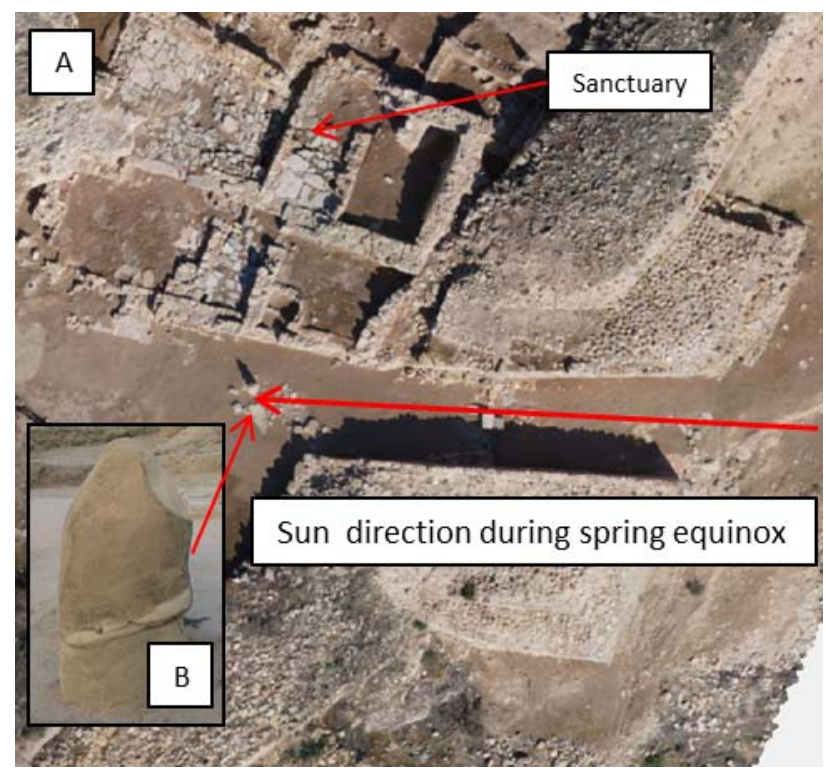

Figure 13. A: Orthoimage $(1 \mathrm{~cm}$ resolution) of the Gate. The orientation of the Gate allows the sun's ray hit an idol (B) interpreted as a goddess (Source: Ruiz and Molinos, 2015).

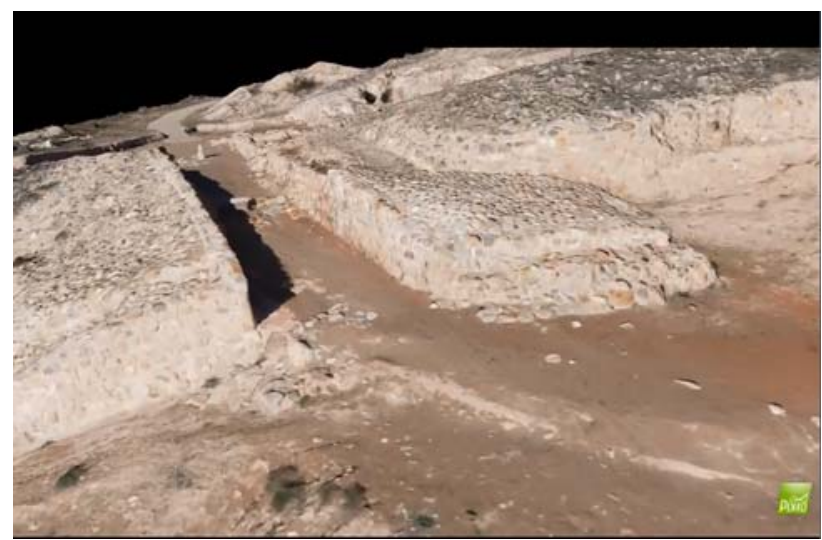

Figure 14. Frame from a walkthrough movie generated from the 3D model of the Gate (created with Pix4D).

\subsection{Burgalimar Castle}

The survey of Burgalimar Castle combines vertical and convergent networks (Table 1 and Figure 2). The oblique network was planned in such a way that stereopairs were also acquired in front of all the walls and towers. The height and distances planned allowed a GSD of $17 \mathrm{~mm}$ at the ground level and the outer walls. However, the GSD at the inner walls was $30 \mathrm{~mm}$ as average since the camera-object distance was near 90 $\mathrm{m}$. Some additional terrestrial images with a compact camera were taken to complete more details in some parts of the inner walls (Figure 15). The camera was a Canon Powershot G10. This camera model has shown its usefulness in previous architectural close range applications carried out by the authors (Cardenal et al, 2012). After orientation, several products were obtained, such as a general ground plan orthoimage and orthoimages of the curtain walls and towers projected onto different planes (Figure 16).

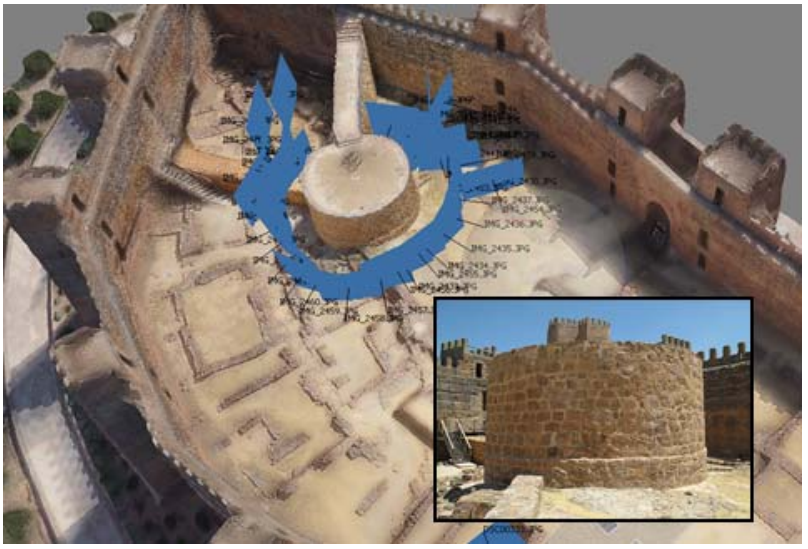

Figure 15. Additional terrestrial network for surveying the inner walls in the ward. Camera was a Canon Powershot G10.

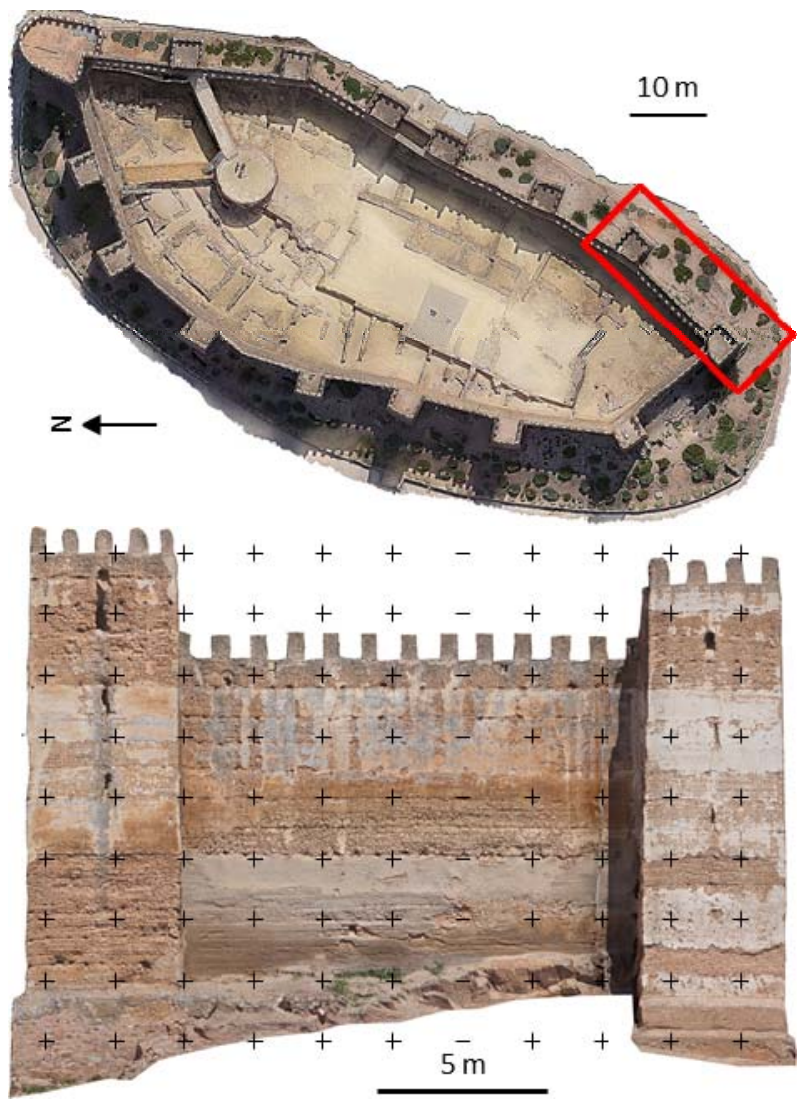

Figure 16.Upper: orthoimage, $2 \mathrm{~cm}$ resolution, of Burgalimar Castle. Lower: orthoimage, $2 \mathrm{~cm}$ resolution, of the SE towers and curtain wall (red box in upper ortho), the ortho is projected onto the plane parallel to the curtain wall. 
Also a DSM and a 3D model with photorealistic textures were generated. The 3D model initially created with PhotoScan was edited with I-Site Studio. The Figure 17 shows the model in stl file format and the 3D printing, printed in plastic filament (3D RepRap x400 printer)
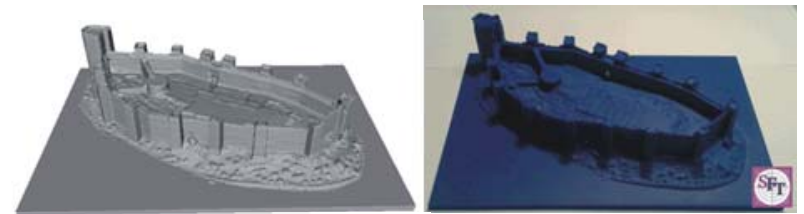

Figure 17. 3D model of the Burgalimar Castle. Left: stl file format model. Right: 3D plastic printed model (3D RepRap x400 printer).

\subsection{Berrueco Castle}

The last case study is the Berrueco Castle (Figure 3). The network was similar to that of Burgalimar Castle, three vertical strips plus two oblique and convergent strips all around the castle at different heights (Figure 18). The Falcon 8 (with the Trinity upgrade) was programmed in cruising mode at a constant velocity of $6 \mathrm{~m} / \mathrm{s}$, so efficiency was improved. The flight parameters and the quality of the georeferencing are shown in Table 1.

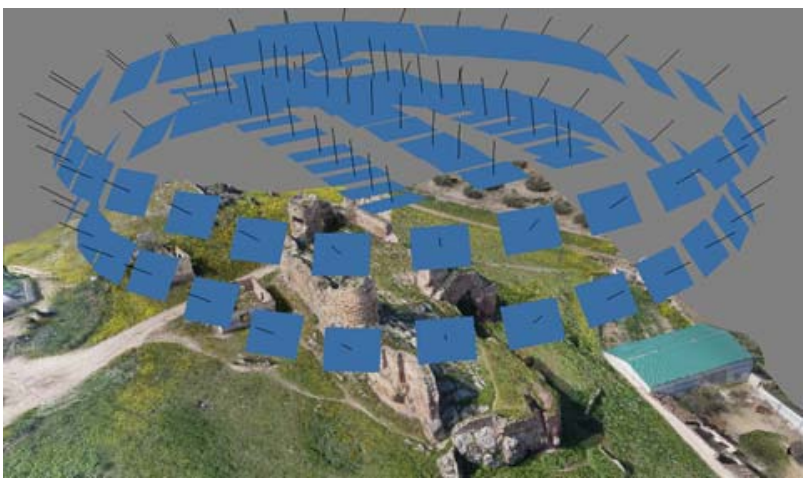

Figure 18. Network geometry at Berrueco Castle (100 images) with Falcon 8.

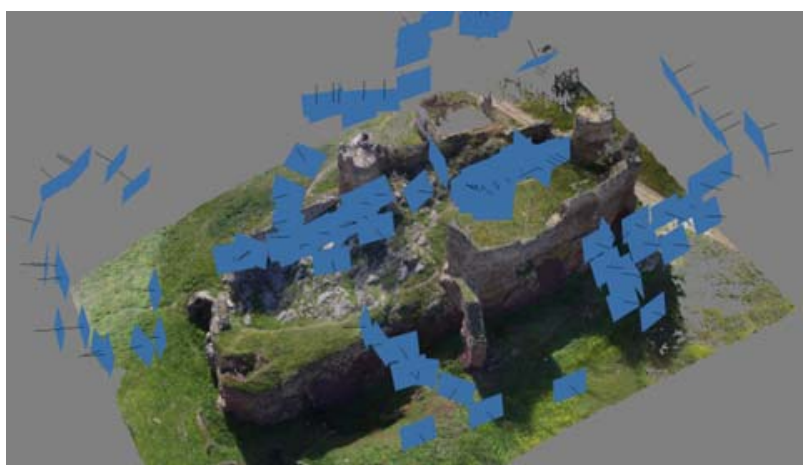

Figure 19. Manual image acquisition mode in the Berrueco Castle with Phantom DJ 3 Advanced.

But this castle has also been documented for a rapid survey as evaluation of a low cost UAS equipped with a small and compact camera (Phantom DJI 3 Advanced / Sony EXMOR camera; Figure 4). This UAS, very easy to fly in manual mode and GPS assisted hover, allows sharp images thanks to the 3axis brushless gimbal that keeps the camera level. Though no photogrammetric flight planning was employed, images were obtained with sufficient overlap suitable for photogrammetric processing (Figure 19). But some gaps were found, since the photographic coverage was not enough, so additional images had to be added.

At first, the image alignment and georeferencing in the Phantom block was calculated using the GNSS information stored in the EXIF data of the image files, giving $3.76 \mathrm{~m}$ as average camera location error. This error was considered acceptable for 3D models for visualization purposes without any metric consideration. In any case, since only 4 GCP appeared in the images, the block was converted to the ETRS89 reference system. No check points were available for quality control.

Finally, both dense point clouds, from Falcon 8 and Phantom DJ, were merged and a single mesh was obtained. Since the camera-object distance in some parts of the castle was closer in the case of the Phantom DJ flight, the level of detail of the final model in some selected parts (battlements and walk-wall) increased (Figure 20).
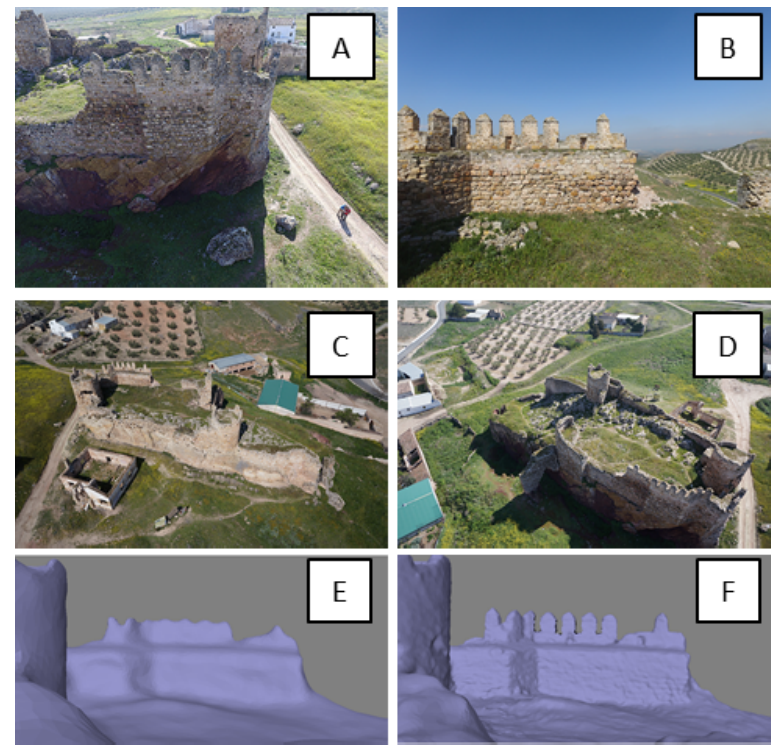

Figure 20. A, B: close range images from the Phantom DJ flight in manual image-acquisition mode; C, D: oblique aerial images from the Falcon 8 in autonomous flight and cruising acquisition mode; E: initial solid model built from the Falcon 8 flight; F: solid model after merging both point clouds and final edition.

Finally, both DSM and 3D model with photorealistic textures were generated. The 3D model initially created with PhotoScan was edited with I-Site Studio. The Figure 21 shows the model in stl file format and the 3D printing (3D RepRap x400 printer).

\section{CONCLUSIONS AND FUTURE WORK}

As conclusion, it has been shown that new UAS techniques are efficient tools for documentation of these historical sites. Vertical images organized in conventional photogrammetric blocks allow those usual mapping products such as maps, orthoimages, DEM, etc. 

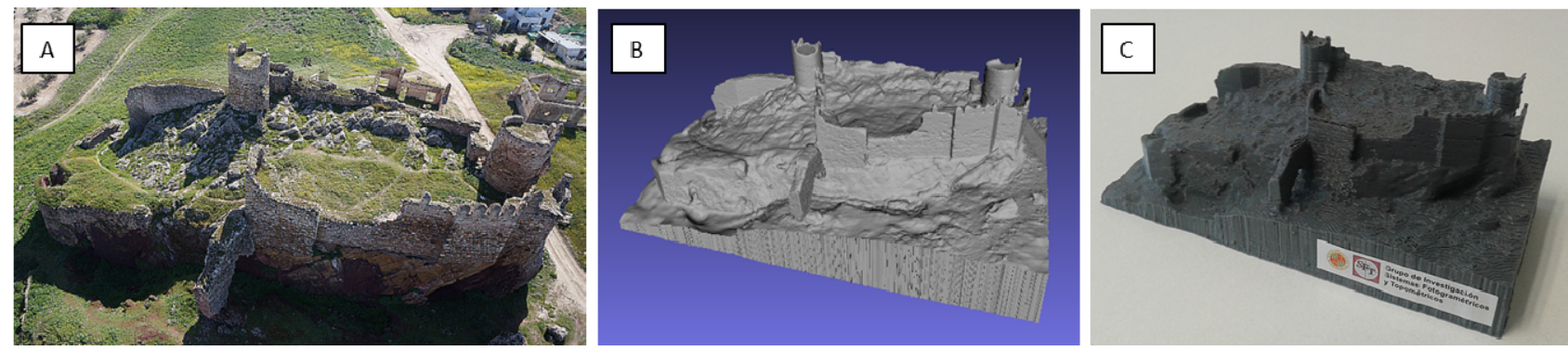

Figure 21. 3D model of the Berrueco Castle. A: aerial Sony NEX5N image from Falcon 8 flight; B: stl file format model. C: 3D plastic printed model (3D RepRap x400 printer).

Oblique stereo and convergent images allow the survey of vertical features (walls and towers). Both vertical and oblique networks strengthen the image block. Also such geometries help to recover the inner parameters. Large overlaps (around 70$80 \%$ ) are recommended to avoid hidden areas and loss of coverage as well as reducing the number of GCP.

In any case, some cautions are needed with respect to the UAS speed, exposure time, wind conditions and flying heights to avoid blurring because the image motion error.

With respect to image processing, indeed the new generation of photogrammetric software based on dense matching and SfM are expanding the possibilities and new application of UAS at relatively low cost, even with small and light non metric cameras.

Products based on dense point clouds are obtained with good relative accuracy and visually attractive visualisations. Although the quality of the absolute georeferencing has been estimated (Table 1) and results have been found acceptable, further analysis about the reliability of the external and inner parameters should be considered, since some inaccuracies still remain when data are exported to conventional DPW.

Additional work is being carried out about this topic. But, as stated by Haala, et al. (2011), despite some remaining problems in absolute accuracy standard mapping products like DSM and ortho images, as well as 3D models, can be generated very well from UAS imagery.

\section{ACKNOWLEDGEMENTS}

The present study has partially been financed by grant TIN2009-09939 (IFOTEL Project) from the Ministry of Science and Innovation, National Programme $\mathrm{R}+\mathrm{D}+\mathrm{I}$, European Regional Development Funds (ERDF-FEDER) and TEP-213 Research Group (PAI, Junta de Andalucía).

\section{REFERENCES}

AscTec, 2016. AscTec Falcon $8+$ AscTec Trinity. Ascending Technologies.

http://www.asctec.de/downloads/public/F8_AscTec-Falcon-8AscTec-Trinity_safety-data-sheet.pdf (30 March 2016).

BOE, 2014. Real Decreto-ley 8/2014, de 4 de julio, de aprobación de medidas urgentes para el crecimiento, la competitividad y la eficiencia, No. 163, 5th July 2014. Spanish regulations on the use of RPAs.
https://www.boe.es/boe/dias/2014/07/05/pdfs/BOE-A-20147064.pdf (30 March 2016).

Buzdugan, A.M., 2013. Levantamiento fotogramétrico de un sector de la muralla "Oppidum Íbero" de Puente Tablas mediante UAV. Bachelor's Degree Thesis, University of Jaen.

Cardenal, J., Perez-Garcia, J.L.; Mata, E.; Hernandez, M.A., Mozas, A., Delgado, J., Lopez-Arenas, A., Meroño, J.E., 2012. Photogrammetric and lidar documentation of the Royal Chapel (Cathedral-Mosque of Cordoba, Spain). International Archives of the Photogrammetry, Remote Sensing and Spatial Information Sciences, Vol. XXXIX, 541-546.

Chabok, M., 2013. Eliminating and modelling non-metric camera sensor distortions caused by sidewise and forward motion of the UAV. International Archives of the Photogrammetry, Remote Sensing and Spatial Information Sciences, Volume XL-1/W2, 73-79.

Eisenbeiss, H. and Sauerbier, M., 2011. Investigation of UAV systems and flight modes for photogrammetric applications. The Photogrammetric Record, 26(136): 400-421.

Eslava-Galán, J., 1999. Los Castillos de Jaen. Ed. Osuna, University of Jaen, 542 p.

Haala, N, Cramer, M., Weimer, F. Trittler, M., 2011. Performance test on UAV-based photogrammetric data collection. International Archives of the Photogrammetry, Remote Sensing and Spatial Information Sciences, Vol. XXXVIII-1/C22. 1-6.

ISPRS, 2013. UAV-g2013. International Archives of the Photogrammetry, Remote Sensing and Spatial Information Sciences (Volume XL-1/W2).

http://www.int-arch-photogramm-remote-sens-spatial-infsci.net/XL-1-W2/ (31 March 2016).

Kraus, K., 2007. Photogrammetry - Geometry from Images and Laser Scans-2nd ed. Walter de Gruyter, Berlin, 459 p.

Ruiz, A. and Molinos, M. (eds.), 2015. Jaen, Tierra Ibera. University of Jaen, 544 p.

Sauerbier, M. and Eisenbeiss, H., 2010. UAVS for the documentation of archaeological excavations. International Archives of Photogrammetry, Remote Sensing and Spatial Information Sciences, Vol. XXXVIII, Part 5. 526-531. 